\title{
Geschafft, erreicht, gewonnen!
}

\section{Christina Aus der Au}

Prof. Dr. theol., Mitglied der Redaktion Ethik

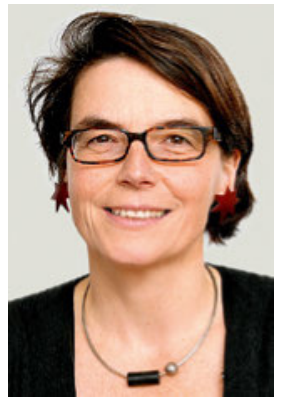

Es ist mir schon etwas peinlich, das zuzugeben. Aber vielleicht bin ich ja nicht die Einzige. Vielleicht gibt es ja noch mehr solche wie mich, solche nämlich, die zwischendurch Computerspiele spielen. Nicht die coolen, herausfordernden Spiele, bei denen man innerhalb der Community gegeneinander spielt, langfristige Anlagen planen oder knifflige Rätsel lösen und gefährliche Gänge herausfinden muss. Nicht die Spiele, bei denen man stolz Levels vergleichen kann oder Punkte. Nein, viel simpler, ohne jeglichen intellektuellen Anspruch, auch braucht es weder blitzschnelle Reaktionen noch herausragende feinmotorische Fähigkeiten. Ich spiele Spiele wie Solitaire oder Bubbleshooter, Jewels oder Tetris. Vor allem dann, wenn ich bei meiner sonstigen Arbeit nicht weiterkomme. Wenn ich feststecke bei einem Artikel, wenn eine schwierige E-Mail sich nicht von selbst schreibt oder wenn mir die zündende Idee fehlt. Schwupp, öffne ich ein Fenster auf meinem Desktop, schaue zuerst etwas verschämt um mich, ob mir auch ja niemand zuschaut, und dann hüpfen meine Finger vergnügt über die Tasten, um die Karten, die Seifenblasen oder die Blöcke an die richtigen Plätze zu verschieben. Und wenn es dann beim dritten oder vierten Versuch endlich aufgeht, wenn die restlichen Karten wie von Zauberhand sich ordnen und verschwinden und die letzten Seifenblasen einer Farbe von selber platzen, dann bin ich befriedigt. Alles gut, alles richtig, alles gelöst.

Dieses Gefühl habe ich in meinem übrigen Leben jenseits der Spiele selten. Immer ist abends noch etwas übriggeblieben, etwas noch nicht erledigt, nicht genügend durchdacht, nicht fertiggelesen, nicht zu Ende besprochen. Und dabei habe ich noch nicht mal in die Zeitung geschaut! Dort ist die Weltlage ja noch viel komplexer, viel unabgeschlossener, viel unbewältigbarer! Wenn ein Problem gelöst ist, dann warten dahinter gleich nochmals zehn.

Kein Wunder, dass ich da immer wieder zu meinen Karten und Seifenblasen zurückkehre! Zu diesen überschaubaren Herausforderungen - und vor allem zu dem guten Gefühl, das Ziel erreicht zu haben. Das Belohnungssystem im Gehirn wird aktiviert, der nucleus accumbens stimuliert ... und wo ist die nächste Befriedigung?

Der griechische Philosoph Aristoteles würde die Stirn seins. Das eine ist das Herstellen. Da hat man am Ende ein Produkt - und alle Bubbles abgeschossen haben, alle Karten geordnet, das ist ebenso ein Produkt wie einen Stuhl herzustellen oder einen Artikel zu schreiben. Die Befriedigung kommt mit dem gelungenen Produkt - aber dann steht auch schon wieder das nächste an. Die andere Art des Tätigseins aber ist diejenige, die ihren Lohn, ihr Glück in sich selber hat. Die nicht erst am Ende befriedigt, sondern schon während man es tut. Musizieren zum Beispiel oder ein spannendes Buch lesen. Oder sich in eine Fragestellung vertiefen, forschen, Menschen begleiten, seinen Beruf ausüben und Freude daran haben. Dasjenige, was ein tschechischer Glücksforscher den 〈flow` nennt. Beides ist nötig, aber um ein gutes Leben zu führen, darf man nicht nur von Produkt zu Produkt springen, sondern sollte seine Ruhe auch in sich selber finden.»

Heute, fast zweieinhalb Jahrtausende später, würde Aristoteles staunen, was wir alles zum Produkt gemacht haben! Erfolg ist das Erreichen einer bestimmten Karriere- oder Gehaltsstufe, Bildung ist ein Abschluss mit Diplom und Papier, und Schönheit ist ein bestimmter Body Mass Index. Und Gesundheit ist dann erreicht, wenn man eine bestimmte Anzahl Schritte oder soundsoviele Flaschen Wasser am Tag abhaken kann. Oder soundsoviele Kalorien, Liegestützen, Joggingrunden. Es ist nicht erstaunlich, dass Fitnesstrackergeräte so beliebt sind. Sie unterstützen das Belohnungshopping ebenso wie meine Spiele es tun. Geschafft, erreicht, gewonnen. Quantifizierbar von einem kleinen Sieg zum nächsten. Das ist natürlich nicht an sich verwerflich. Sich auf die kleinen Schritte zu konzentrieren hilft, die grossen Ziele zu erreichen. Aber beides bleibt im Modus des Erreichens, der Produkte. Je simpler, desto effektiver.

Das Gehirn wird so konditioniert auf kontinuierliche Produktbelohnungen. Häppchenweise, immer wieder und dann immer schneller wieder. Und alles, was einen langen Atem verlangt, sorgfältige Vertiefung in die Materie, was nicht gleich sofortig ein Resultat zeigt, kompliziert ist, unlösbar sogar, hat demgegenüber schon verloren.

Ich müsste mir vielleicht doch überlegen, ob ich Solitaire und Tetris nicht ganz aus meinem Repertoire löschen sollte. 